\title{
Knee Braces and Anti-Inflammatory Sleeves in Osteoarthritis, Innovation for the 21st Century?
}

Paul Y F Lee ${ }^{1,2^{*}}$, James Brock ${ }^{1}$, Sarah Mansoor ${ }^{1}$ and Bethan Whiting ${ }^{1}$

${ }^{1}$ Lincolnshire Elective Orthopaedics Institute, Grantham and District Hospital, Manthorpe Road, Grantham, NG31 8DG, UK

${ }^{2}$ School of Sport and Exercise Science, University of Lincoln, Brayford Pool, Lincoln, LN6 7TS, UK

*Corresponding author: Prof. Paul Y F Lee, Lincolnshire Elective Orthopaedics Institute, Grantham and District Hospital, Manthorpe Road, Grantham, NG31 8DG, UK, Tel: +447764614688; E-mail: plee@lincoln.ac.uk

Received date: April 04, 2018; Accepted date: April 06, 2018; Published date: April 10, 2018

Copyright: (C) 2018 Lee PYF, et al. This is an open-access article distributed under the terms of the Creative Commons Attribution License, which permits unrestricted use, distribution, and reproduction in any medium, provided the original author and source are credited.

\section{Background}

In the UK, approximately 8.75 million people aged 45 and over $(33 \%$ of the populations) have sought treatment for Osteoarthritis (OA) [1]. Data suggests that the greatest proportion of this demographic (4.11 million or $6.1 \%$ of the population) suffer from OA of the knee joint [2]. Statistics from Arthritis Research UK indicate that after a total knee replacement, $22.3 \%$ of patients report moderate to severe pain in the immediate post-operative period (up to four weeks) (Arthritis Research UK, [2]). The epidemiological data clearly indicates that osteoarthritis of the knee accounts for a sizeable proportion of the current healthcare burden and morbidity amongst the UK population. Whilst surgical intervention should be viewed as a final but not definitive solution, further data suggests there is a need to maximize conservative management.

\section{Evidence for Knee Braces}

A Cochrane Review by Duivenvoorden et al. looked at the effect of braces and orthoses on Knee OA. Four randomized controlled clinical trials compared a valgus knee brace against no treatment. Of the four studies, three showed minor improvements in pain, function and health-related quality of life, which were of statistical significance [4-6]. The other study reported improvement, however this failed to reach significance [3]. Notably, none of the studies looked at the delay of surgery as an outcome. The aim of a mechanical knee brace is to unload the diseased compartment, in contrast to neutral braces and sleeves which are thought to immobilise and stabilise the knee joint by providing tactile feedback from the skin. Mechanical knee braces such as the Unloader One (Figure 1) have been shown to be superior to neoprene sleeves and other models in some studies $[7,8]$.

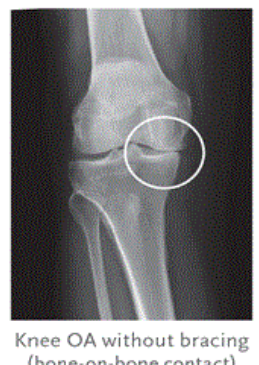
(bone-on-bone contact)

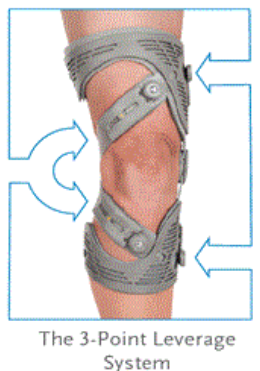

System

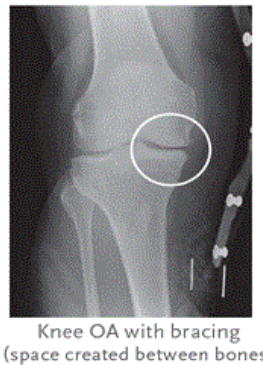

(space created between bones)
Figure 1: Show the function of mechanical knee brace (Unloader one, courtesy of ossur).
Furthermore, they have been shown to be a cost-effective method to bridge and delay surgery in uni-compartmental arthritis [9-11]. There is little evidence suggesting that neoprene type knee sleeves provide any support or have any effect on the knee.

\section{Germanium Embedded Anti-inflammatory Knee Brace Technology}

Germanium is a semiconductor metalloid in the carbon group, positioned between tin and silicone in the periodic table. Predicted and named ' ekasilicon' by Dimitri Mendeleev in 1869, its discovery in 1886 allowed widespread usage in electronics and optics (RSC 2017). Germanium is non-essential for life and its organic compounds are non-toxic [12]. In alternative medicine, oral synthetic germanium compounds have shown some benefit in rheumatoid arthritis, its semiconductor properties in other ways to aid in the management of arthritis.

In contrast to metals, as temperature increases the resistance of a semiconductor, such as Germanium, decreases. Conducting properties may be altered by the deliberate introduction of impurities in the crystal lattice structure at 'semiconductor junctions' also known as 'doping'. Germanium has four electrons in its outer shell (Figure 2), termed 'valence' electrons. Valence electrons attribute electrical properties to the atom and therefore to the solid compound [13]. Germanium, at certain temperatures, has more 'free' electrons and allows a higher conductivity. It is hypothesized that the electrons would therefore be released in a specific direction when they faced a certain temperature and believe to have a 'trans-dermal' effect. It has been proposed that cotton garments imbedded with Germanium and Carbon would utilize the trans-dermal effect to create a micro electromagnetic field, which leads to increase circulation and may have a role in the inflammatory process (Figure 3 ).

A clinical study looked at the effects of germanium socks on 66 nurses and staff members over a 15 day period. It demonstrated $50 \%$ reduction in pain, fatigue and swelling on a Visual Analogue Scale (VAS). In the sports recovery field, a clinical study looked at injuries and games missed within an American major league soccer team. The total number of injuries was 14 in 2014, 14 in 2015 and 13 in 2016 when Germanium brace products were used. The average number of days missed reduced from 16.4 in 2015 to 10 in 2016 with the use of a Germanium sleeve. Although these are low level observational studies, it suggests that Germanium infused garments have some clinical effects and may have a role in osteoarthritis. 
Citation: Lee PYF, Brock J, Mansoor S, Whiting B (2018) Knee Braces and Anti-Inflammatory Sleeves in Osteoarthritis, Innovation for the 21st Century?. J Arthritis 7: e117. doi:10.4172/2167-7921.1000e117

Page 2 of 2

\section{2: Germanium $\quad 2,8,18,4$}

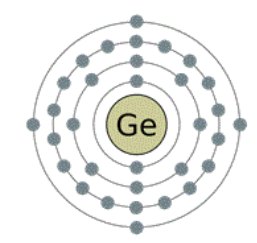

Figure 2: Show germanium has 32 electron and has four electrons in its outer shell.
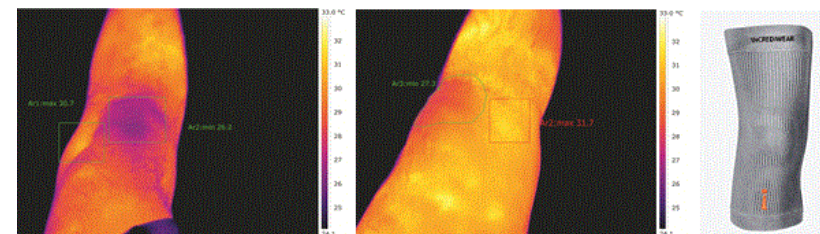

Figure 3: Shows before and after thermographs, suggested increase of heat cause by increase in microcirculation. Germanium embedded knee sleeve. (courtesy of incrediwear).

\section{Conclusion}

Knee OA continues to be a leading source of morbidity within the UK population, optimization of conservative treatment remains important in delaying the need for surgical intervention. Offloading knee braces for uni-compartmental arthritis have demonstrated minor improvements in pain and function when compared to controls. Research is yet to compare various models and types of offloading knee brace. Initial germanium product uses have begun to demonstrate that innovations in anti-inflammatory sleeve technology may be beneficial. More evidence is needed to explore its role in osteoarthritis.

\section{References}

1. Arthritis UK data and statistics report (2017).

2. Arthritis Research UK (2018) State of musculoskeletal health 2017.

3. Brouwer RW, Raaij TM, Verhaar JAN, Coene LNJEM, Bierma-Zeinstra SMA (2006) Brace treatment for osteoarthritis of the knee: a prospective randomized multi-centre-trial. Osteoarthritis Cartilage 14: 777-783.

4. Kirkley A, Webster-Bogaert S, Litchfield R, Amendola A, MacDonald S, et al. (1999) The effect of bracing on varus gonarthrosis. J Bone Joint Surg Am 4: 539-547.

5. Müller-Rath R, Cho HY, Siebert CH, Miltner O (2011) Clinical and gait analytical investigation of valgus knee bracing in therapy for medial degenerative joint disease of the knee [Klinische und ganganalytische Untersuchungeiner valgisierenden Kniegelenkentlastungsorthese in der Therapie der medialen Gonarthrose]. Zeitschrift für Orthopädie und Unfallchirurgie 149: 160-165.

6. Sattari S, Ashraf A (2011) Comparison of the effects of 3-point valgus knee support and lateral wedge insoles in medial compartment knee osteoarthritis. Iran Red Crescent Med J 13: 624-628.

7. Richards J, Sanchez-Ballester J, Jones RK, Darke N, Livingstone BN (2005) A comparison of knee braces during walking for the treatment of osteoarthritis of the medial compartment of the knee. J Bone Joint Surg Br 87: 937-939.

8. Dessery Y, Belzile ÉL, Turmel S, Corbeil P (2014) Comparison of three knee braces in the treatment of medial knee osteoarthritis. Knee 21: 1107-1114.

9. Lee P, Winfield T, Harris S, Storey E, Chandratreya A (2017) Unloading knee brace is a cost-effective method to bridge and delay surgery in unicompartmental knee arthritis. BMJ Open Sport Exercise Medicine 2: e000195.

10. Schiphof D, van den Driest J, Runhaar J (2018) Osteoarthritis year in review 2017: rehabilitation and outcomes. Osteoarthritis Cartilage 26: 326-340.

11. Gerber GB, Léonard A (1977) Mutagenicity, carcinogenicity and teratogenicity of germanium compounds. Mutat Res 387: 141-146.

12. http://hyperphysics.phy-astr.gsu.edu/hbase/Solids/sili.html

13. http://www.rsc.org/periodic-table/element/32/germanium 